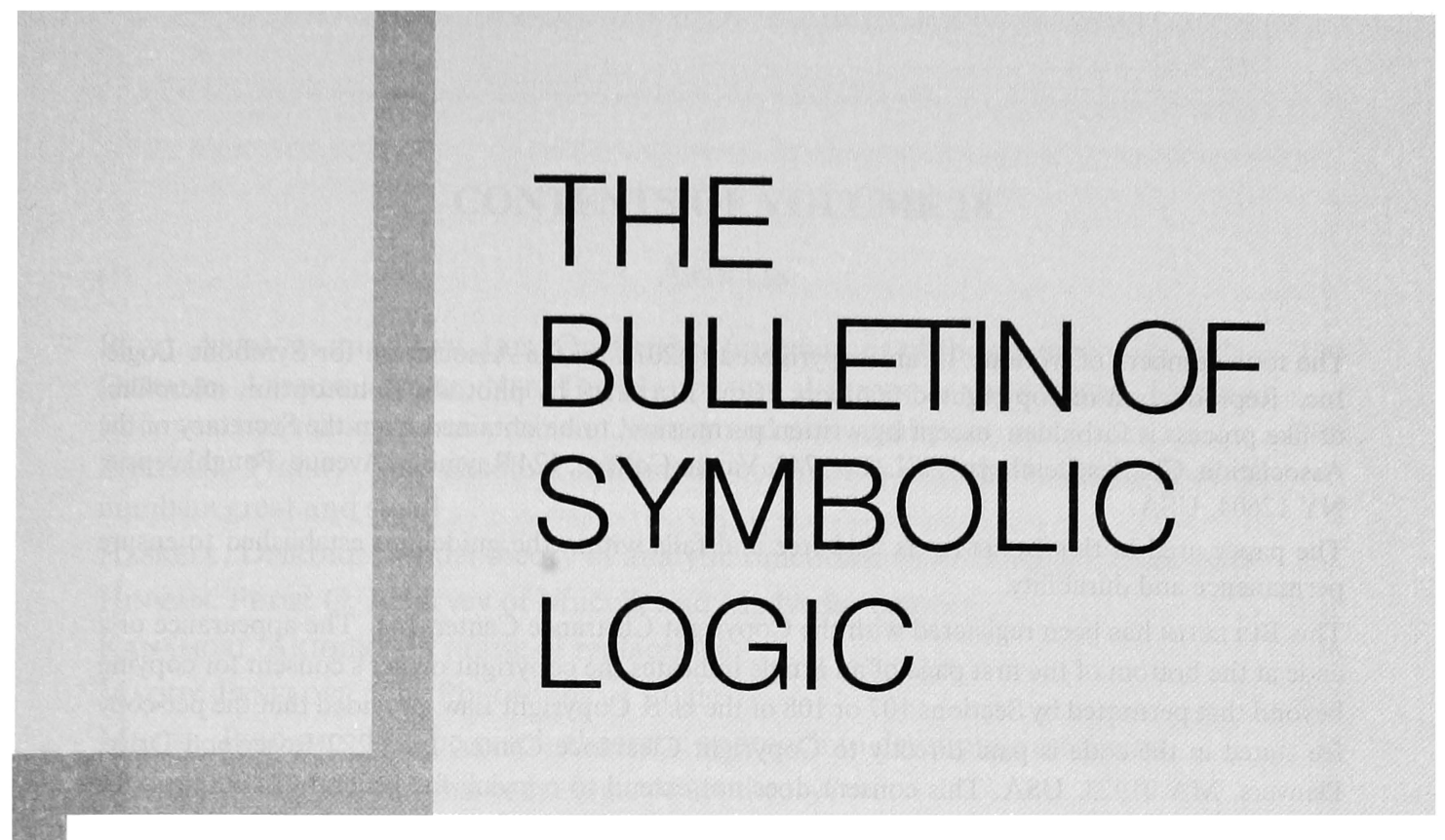

Edited by

John Baldwin, Managing Editor

Volker Halbach Martin Otto

Deirdre Haskell Michael Rathjen

Menachem Kojman Erich Reck

André Nies

Reviews Editors

Steve Awodey, Managing Editor for Reviews

John Burgess

Ernest Schimmerling

Mark Colyvan

Alex Simpson

Anuj Dawar

Kai Wehmeier

Noam Greenberg

Matthias Wille

Rahim Moosa 
The four numbers of Volume 18 are copyrighted (C2012 by the Association for Symbolic Logic, Inc. Reproduction of copyrighted numbers of the BULLETIN by photostat, photoprint, microfilm, or like process is forbidden, except by written permission, to be obtained from the Secretary of the Association, Charles Steinhorn, ASL, Box 742, Vassar College, 124 Raymond Avenue, Poughkeepsie, NY 12604, USA.

The paper used in this BULLETIN is acid-free and falls within the guidelines established to ensure permanence and durability.

This BULLETIN has been registered with the Copyright Clearance Center, Inc. The appearance of a code at the bottom of the first page of an article indicates the copyright owner's consent for copying beyond that permitted by Sections 107 or 108 of the U. S. Copyright Law, provided that the per-copy fee stated in the code is paid directly to Copyright Clearance Center, Inc., 222 Rosewood Drive, Danvers, MA 01923, USA. This consent does not extend to copying for general distribution, for advertising or promotion purposes, for creating new collective works, or for resale. Specific written permission for such copying must be obtained from the Association. 


\title{
CONTENTS OF VOLUME 18
}

\begin{abstract}
ArTiCLes
BetTI, ARIANNA and LoEB, IrIs. On Tarski's foundations of the geometry of solids . 230 Durand, Arnaud, Jones, Neil D., Makowsky, Johann A., and More, Malika. Fifty years of the spectrum problem: Survey and new results ................ 505

EHRLICH, PHILIP. The absolute arithmetic continuum and the unification of all

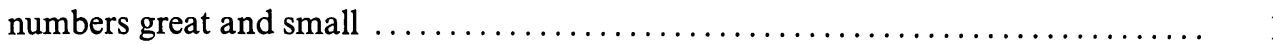

HASKELl, DeIRDRE. Model theory of analytic functions: some historical comments 368

Hinman, Peter G. A survey of Mučnik and Medvedev degrees ............... 161

KANAMORI, AKIHIRO. In praise of replacement ......................... 46

Maddy, PeneloPe. The Philosophy of Logic ........................... 481

MiLLER, BENJAMIN D. The graph-theoretic approach to descriptive set theory ..... 554

VÄ̈̈NÄNEN, Jouko. Second order logic or set theory? .................... 91

VisSER, ALBERT. Vaught's Theorem on Axiomatizability by a Scheme ........... 382

vON PLATO, JAN. Gentzen's proof systems: byproducts in a work of genius . ...... 313
\end{abstract}

\section{COMMUNICATIONS}

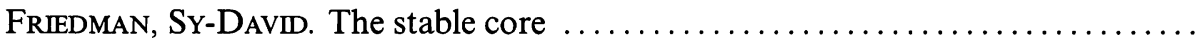

REVIEWS

A. S. Kechris, B. Löwe, and J. R. Steel (editors), Games, scales, and Suslin cardinals. The Cabal Seminar, Volume I. Reviewed by Alessandro Andretta ........... 122 R. Downey and D. Hirschfeldt, Algorithmic randomness and complexity. Reviewed by Laurent Bienvenu . . . . . . . . . . . . . . . . . . . . . . . . . . . . . . . . . . . G. Sommaruga (editor), Foundational theories of classical and constructive mathematics. Reviewed by Roy T. Cook

Several papers concerning computable categoricity. Reviewed by Daniel Turetsky .

L. Haaparanta (editor), The development of modern logic. Reviewed by Alasdair Urquhart

A. G. Burgess and J. P. Burgess, Truth. Reviewed by Volker Halbach........... 271

A. L. Mann, G. Sandu, and M. Sevenster, Independence-friendly logic. Reviewed by Julian Bradfield.

I. Welty, Frege on indirect proof. Reviewed by Matthias Wille ................

L. Horsten, The Tarskian Turn: deflationism and axiomatic truth. Reviewed by Martin Fischer.

E. Casanovas, Simple theories and hyperimaginaries. Reviewed by Bradd Hart..... 403

$\mathrm{J}$. Väänänen, Models and games. Reviewed by Ian Hodkinson ...................
A. Urquhart, Henry $M$. Sheffer and notational relativity. Reviewed by Matthias Wille. 
Various papers on $\Pi_{1}^{0}$ classes. Reviewed by Douglas Cenzer ............. 409

J. Krajíček, Forcing with random variables and proof complexity. Reviewed by Sam Buss

Several papers on automatic randomness. Reviewed by Mia Minnes

IN MEMORIAM

Ernst Specker (1920-2011).

MeEtings of THe Association fOR Symbolic Logic

2011 Spring Meeting of the Association for Symbolic Logic, Hilton San Diego Bayfront Hotel, San Diego, California, USA, April 21-22, $2011 \ldots \ldots \ldots \ldots \ldots \ldots$ 2010-2011 Winter Meeting of The Association for Symbolic Logic, New Orleans Marriott and Sheraton New Orleans Hotels, New Orleans, LA, USA, January 8-9,

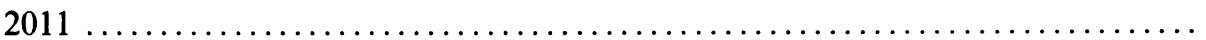
2011 North American Annual Meeting of the Association for Symbolic Logic , University of California at Berkeley, Berkeley, CA, USA, March 24-27, $2011 \ldots \ldots$. 2011 European Summer Meeting of the Association for Symbolic Logic, Logic Colloquium '11, Barcelona, Catalonia, Spain, July 11-16, 2011

MeEtings SPONSORED by THE AsSOciation fOR Symbolic Logic

XVI Brazilian Logic Conference (EBL 2011), Petrópolis, Rio de Janeiro, Brazil, May 9-13, 2011

18th Workshop on Logic, Language, Information and Computation (WoLLIC

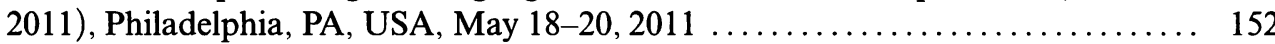

Notices $154,306,477,640$

Officers and Committees of the Association for Symbolic Logic 581 Members of the Association 586 
Articles and Communications being submitted for publication in the BuLLETIN should be sent to one (and only one) of the following editors: John Baldwin (Managing Editor), Dept. of Math., Stat., and Comp. Sci. (M/C 249), Univ. of Ill. at Chicago, 851 S. Morgan St., Chicago, IL 60607, USA (jbaldwinquic.edu); or Volker Halbach, New College, Oxford, OX1 3BN, UK (volker .halbach@philosophy.ox.ac.uk); or Deirdre Haskell, Department of Mathematics and Statistics, McMaster University, 1280 Main St. W, Hamilton ON L8S 4K1, Canada (haskell@math.mcmaster. ca); or Menachem Kojman, Department of Mathematics, Ben Gurion University of the Negev, P.O.B. 653, Be'er-Sheva 84105, Israel (kojman@math . bgu . ac . il); or André Nies, Department of Computer Science, University of Auckland, Private Bag 92019, Auckland, New Zealand (nies . editor@gmail.com); or Martin Otto, Department of Mathematics, Technische Universität Darmstadt, Schlossgartenstr. 7, 64289 Darmstadt, Germany (ot to@mathematik.tu-darmstadt .de); or Michael Rathjen, School of Mathematics, University of Leeds, Leeds LS2 9JT, UK (rathjen@maths . leeds . ac .uk); or Erich Reck, Department of Philosophy, University of California Riverside, HMNSS Building Room 1604, 900 University Avenue, Riverside, CA 92521, USA (erich.reck@ucr.edu). Submissions that are not readily categorized as either Articles or Communications should be sent to the managing editor.

Books for review in the Bulletin should be sent to ASL, Box 742, Vassar College, 124 Raymond Avenue, Poughkeepsie, NY 12604, USA. The Managing Editor for Reviews is Steve Awodey, Department of Philosophy, Carnegie Mellon University, 135 Baker Hall, Pittsburgh, PA 15213, USA (awodey@cmu .edu). The other editors of reviews are John Burgess (jburgess $₫$ princeton.edu), Mark Colyvan (mcolyvan@usyd.edu.au), Anuj Dawar (Anuj.Dawar@cl. cam. ac.uk), Noam Greenberg (Noam.Greenberg@mcs.vuw.ac.nz), Rahim Moosa (rmoosa@ math.uwaterloo.ca), Ernest Schimmerling (eschimme@andrew.cmu.edu), Alex Simpson (Alex.Simpson@ed.ac.uk), Kai Wehmeier (wehmeier@uci.edu), and Matthias Wille (matthias.wille@iel.uni-koeln.de).

The editors prefer electronic submissions. The preferred formats for electronic submissions are PDF or postscript, but other formats, such as Word documents, will be accommodated as best as possible. The author should keep a complete copy of the submitted manuscript and the electronic files from which it was created. After the paper is accepted in its final form, an electronic copy will be appreciated and will advance the final publication date of the paper. It is preferred that papers be prepared in $\mathrm{LT}_{\mathrm{E}} \mathrm{X}$ or other variant of $\mathrm{T}_{\mathrm{E}} \mathrm{X}$, especially for manuscripts that include extensive symbolic or mathematical notation. The ASL ITEX style files are available at http://www.aslonline.org, but their use is optional. Fifty offprints of each article are supplied at no charge; additional offprints may be purchased if desired.

Postscript files of articles published in the BuLLETIN may be downloaded using a Web browser from http://www.math.ucla.edu/ asl/bsltoc.htm. All volumes of the BULLETIN also are available online in the JSTOR database.

Requests for information, applications for membership, orders for back volumes, business correspondence, and notices and announcements for publication in the BuLLETIN should be sent to the Secretary-Treasurer of the Association, Charles Steinhorn, ASL, Box 742, Vassar College, 124 Raymond Avenue, Poughkeepsie, NY 12604, USA. The electronic mail address of the Association's business office is asl@vassar. edu. The ASL Website is located at http://www. aslonline.org. Links from that site provide further information on the BULLETIN and on submitting papers for publication.

Notices of change of address, dues payments, and subscription orders to the JourNal and BULLETIN should be sent to: Association for Symbolic Logic, c/o American Mathematical Society, 201 Charles Street, Providence, RI 02904-2294, USA. All orders must be accompanied by payment in US dollars; Visa, MasterCard, Discover and American Express charges are accepted. To receive a replacement copy of the BULLETIN, please report damaged, defective, or missing issues within nine months of the date of publication.

For subscriptions to the REVIEW, contact Cambridge Journals Customer Services at journals $₫$ cambridge.org.

All back volumes of the BULLETIN are available, from the Office of the Secretary-Treasurer who has information on prices and discounts to individual and institutional members.

The paper used in this BuLLETIN is acid-free and falls within the guidelines established to ensure permanence and durability. 


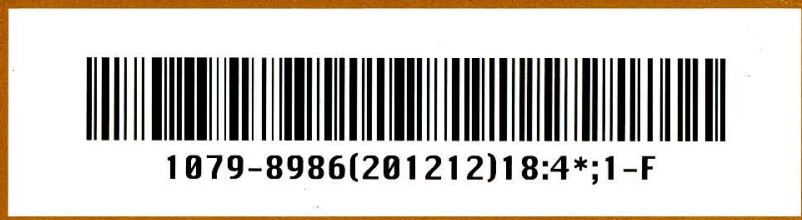

Published online by Cambridge University Press 